\title{
Religious affiliation and experience of Bang Chan males, by age group, 1949
}

\begin{tabular}{|c|c|c|c|c|c|c|c|}
\hline \multirow{2}{*}{$\begin{array}{l}\text { Age } \\
\text { group }\end{array}$} & \multirow{2}{*}{$\begin{array}{l}\text { Total } \\
\text { males }\end{array}$} & \multicolumn{2}{|c|}{ Moslem males } & \multicolumn{2}{|c|}{ Buddhist males } & \multicolumn{2}{|c|}{ Buddhist priests ${ }^{\mathrm{a}}$} \\
\hline & & No. & $\%$ & No. & $\%$ & No. & $\%^{\mathrm{b}}$ \\
\hline $0-4$ & 78 & 3 & 4 & 75 & 96 & & \\
\hline $5-9$ & 108 & 8 & 7 & 100 & 93 & & \\
\hline $10-14$ & 98 & 3 & 3 & 95 & 97 & & \\
\hline $15-19$ & 109 & 7 & 6 & 102 & 94 & 10 & $10^{\mathrm{c}}$ \\
\hline $20-24$ & 93 & 9 & 10 & 84 & 90 & 39 & 46 \\
\hline $25-29$ & 58 & 5 & 9 & 53 & 91 & 37 & 70 \\
\hline $30-34$ & 52 & 6 & 12 & 46 & 88 & 32 & 70 \\
\hline $35-39$ & 45 & 4 & 9 & 41 & 91 & 27 & 66 \\
\hline $40-44$ & 47 & 3 & 6 & 44 & 94 & 35 & 79 \\
\hline $45-49$ & 44 & 1 & 2 & 43 & 98 & 35 & 81 \\
\hline $50-54$ & 28 & 3 & 11 & 25 & 89 & 21 & 84 \\
\hline $55-59$ & 23 & 3 & 13 & 20 & 87 & 14 & 70 \\
\hline $60-64$ & 22 & 3 & 14 & 19 & 86 & 13 & 68 \\
\hline $65-69$ & 14 & & & 14 & 100 & 10 & 71 \\
\hline $70-74$ & 8 & 2 & 25 & 6 & 75 & 5 & 83 \\
\hline $75-79$ & 2 & & & 2 & 100 & 2 & 100 \\
\hline $80-84$ & 3 & & & 3 & 100 & 3 & 100 \\
\hline All ages & 832 & 60 & 7 & $\overline{772}$ & 93 & 283 & \\
\hline \multicolumn{2}{|c|}{ Age 20 and above } & & & 400 & & 273 & 68 \\
\hline
\end{tabular}

${ }^{a}$ Have been or are ordained priests in Bang Chan or elsewhere.

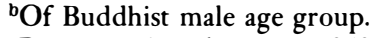

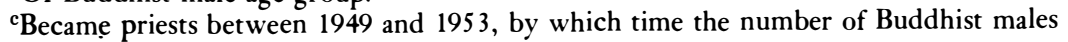
aged 15-19 had been reduced to 92 . 